\title{
Questionamentos sobre uma educação problematizante: pedagogia do conceito e possibilidades de resistência ${ }^{1}$
}

\section{Paola Sanfelice Zeppini}

\section{Resumo}

Em diversas obras, Deleuze insistiu na necessidade de se dedicar especial atenção aos problemas e à forma como são colocados. A pedagogia do conceito é a idade do conceito que permite à filosofia resistir aos seus rivais, na medida em que mostra que a criação conceitual é efetuada sempre em função de problemas que se impõem a cada filósofo e que não podem ser limitados à veracidade ou falsidade de suas soluções. Operando ressonâncias entre os campos da filosofia e da educação, o presente texto tem como proposta levantar questionamentos sobre como a educação pode funcionar de forma a liberar outras formas de pensar e de agir a partir de uma postura problematizante e autoproblematizante.

Palavras-chave: Problema; Filosofia; Educação.

\section{Resumen}

En varias obras Deleuze ha insistido en la necesidad de dedicarle una atención especial a los problemas y al modo como esos son puestos. La pedagogía del concepto es la edad del concepto que permite a la filosofía resistir a sus rivales, pues muestra que la creación conceptual es efectuada siempre en función de los problemas que se imponen a cada filósofo y que no pueden estar limitados ni a la veracidad ni a la falsedad de sus soluciones. Operando resonancias entre los campos de la filosofía y de la educación, la propuesta es a hacer cuestionamientos de cómo la educación puede liberar otros modos de pensar y de accionar a partir de una postura problematizante y autoproblematizante.

Palabras clave: Problema; Filosofía; Educación.

\footnotetext{
${ }^{1}$ Texto apresentado no II Congresso da SOFIE como comunicação de resultados parciais da pesquisa de doutorado em andamento com o apoio financeiro da Capes.

${ }_{2}^{2}$ Doutora em Educação, na área de Filosofia e História da Educação, pela Faculdade de Educação da Unicamp. Mestre em Filosofia e graduada em História pela mesma universidade.
} 
$\mathrm{P}$ ode-se dizer que uma inquietação quanto à noção de problema percorre a construção da filosofia de Deleuze e segundo a qual é possível mapear seus diversos encontros com outros filósofos, escritores, pintores, filmes, etc. ${ }^{3}$ Tal inquietação marca fortemente seus estudos sobre a filosofia de Bergson e também suas críticas à imagem dogmática do pensamento. Na leitura deleuziana, a intuição bergsoniana funciona como método problematizante que nos lança à duração como este tempo contínuo, heterogêneo e em constante diferenciação no qual verdadeiros problemas se colocam. No que se refere à critica da imagem dogmática do pensamento, a desconstrução dos oito postulados que a constituem é feita sempre em função de problemas, da forma como eles são inventados e criam os sentidos que compõem a imagem que a filosofia se dá do que significa pensar.

Em $O$ que é a filosofia? (1997), Deleuze e Guattari afirmam que a filosofia é criação de conceitos e que esta criação só pode ser feita em função dos problemas que se impõem a cada pensador. Para que um pensamento efetivo seja posto em movimento, lemos em Diferença $e$ repetição (1988), é preciso que sejam verdadeiros problemas, quer dizer, que não sejam determinados em função das soluções que viriam satisfazêlos. "Pensar é criar" (Deleuze, 1988, p. 145), e para criar é preciso liberar-se de pressupostos que determinam e limitam o que pode ser pensado, tarefa que só pode ser empreendida em meio a um campo problemático que nos obrigue a criar novas e diferentes maneiras de responder aos problemas que não são decalcados a partir de suas soluções.

Essa definição da filosofia como criação de conceitos compõe, juntamente com a tarefa de resistir à ameaça da formação profissional comercial, a noção de pedagogia do conceito. É esta noção, segundo os autores, que nos impede de cair no mundo das opiniões que despontencializa o pensamento ao limitá-lo a atos de recognição e/ou a

\footnotetext{
${ }^{3}$ Além da grande incidência do tema ao longo da produção deleuziana e que não seria possível mapear no contexto do presente trabalho, podemos citar uma carta escrita por Deleuze (2015, p. 77-78) a Arnaud Villani, na qual o filósofo relata seu interesse e uma "necessidade de construir um conceito de problema" e a forma como isso o teria levado a "procurar em cada caso como um problema pode ser colocado" (tradução nossa).
} 
formas de sensibilização que associam conceitos abstratos a produtos comerciais. A pedagogia do conceito é a idade do conceito que opera resistências justamente em função de sua capacidade de ensinar algo, sua capacidade de funcionar em função de problemas que não se satisfazem com a veracidade ou falsidade de suas possíveis soluções. Neste sentido, é possível questionar: de que modo a noção de pedagogia do conceito pode nos ajudar a pensar uma educação problematizante?

Ao longo do percurso intelectual de Deleuze, é possível observar a passagem de uma noção de conceito como dado - que representa um mundo possível e imutável -, para outra que o toma como criação - móvel e flexível -, oferecendo as condições necessárias para a elaboração da noção de pedagogia do conceito que funcionará "na análise das condições de criação de conceitos" e ganhará "relevância ao apontar para uma construção que efetivamente pensa a diferença em si mesma" (LA SALVIA, 2015, p. 29). Cada tipo de conceito corresponde a diferentes formas de pensar e de definir o que significa pensar. Não se trata, neste sentido e como salienta Bianco (2005, p. 1293), de tomar a pedagogia do conceito como "uma prática pedagógica que utiliza o conceito como seu instrumento privilegiado", mas do sentido pedagógico que faz parte do próprio conceito como ato do pensamento.

Em ressonância com estudos feitos em companhia de Deleuze e de Bergson, podemos dizer que se trata da potência educativa do próprio conceito na medida em que este, ao não buscar mais responder à questão $o$ que é?, a essência ou o resultado da coisa, mas, ao contrário e como diria Bergson, pensar em progressos e buscando as nuanças, ou como diria Deleuze, questionar o quando, o como e o de que maneira, nos lança a um outro tipo de pensamento. O conceito é assinado e datado porque é criação singular que se dá em função dos problemas que se impuseram ao filósofo. Não se trata, portanto, de uma qualidade restrita a um conceito ou a uma filosofia específica, pois a pedagogia do conceito é uma "idade do conceito" e a única que nos permite sair dos Universais, do jogo de opostos, que como diz Bergson, são extremamente largos e podem servir a qualquer realidade, Junho-Setembro de 2017 - ISSN 1984-9605 - p. 86-97 
assim como nos alertam Deleuze e Guattari, nos impedir de cair no desastre absoluto do mundo das opiniões.

Parece interessante, então, perguntar: não seria este também o papel da própria educação? Não existiria na educação a potência de nos colocar em meio às diferentes formas do pensamento, nos lançando à experiência de outras imagens do pensamento e nos forçando a pensar efetivamente o que tem significado, em nossos dias atuais, pensar? De que modo a educação pode operar formas de resistência ao mundo das opiniões e a esta imagem dogmática que despotencializam o pensamento e o reduzem, ora a simples atos de recognição e a procura da melhor forma de adaptação aos problemas e soluções já dados, ora a formas de comercialização de produtos e serviços? Como fazer funcionar, nas experiências mais cotidianas, uma educação problematizante e autoproblematizante?

Segundo La Salvia, a pedagogia do conceito tem a dupla tarefa de dar consistência a uma definição de filosofia como criadora de conceitos e de escapar dos conceitos do marketing. Segundo esse autor, o trabalho de crítica à imagem dogmática do pensamento desenvolvida por Deleuze ao longo de obras anteriores, permite aos autores de $O$ que é a filosofia? colocarem a pedagogia do conceito não apenas como uma forma de estudar a história da filosofia a partir do campo problemático de cada filósofo, e assim lançar uma nova imagem do pensamento, como também determinar as relações entre filosofia e criação de um modo diferente daquele feito por filósofos que remeteram a "criação a uma pura subjetividade" (DELEUZE; GUATTARI, 1997, p. 21). Ao "analisar as condições de criação como fatores de momentos que permanecem singulares" (DELEUZE; GUATTARI, 1997, p. 21), a pedagogia do conceito oferece à filosofia a possibilidade de resistir a estes três rivais: àqueles "que não se ocuparam o bastante com a natureza do conceito como realidade filosófica"4, àqueles

\footnotetext{
${ }^{4}$ La Salvia (2015, p. 23-24) mostra, no capítulo 1 de sua tese, como a primeira incidência do termo pedagogia do conceito, na introdução de $O$ que é a filosofia? (cf. DELEUZE; GUATTARI, 1997, p. 20-21), traça os contornos gerais do que podemos chamar de "inimigos" desta idade do conceito. O autor afirma que aqueles que "não se ocuparam o bastante com a natureza do conceito como realidade filosófica" são os que "fazem uma imagem dogmática do pensamento".
} 
que os tomaram como criação, mas os mantiveram a serviço de um espírito absoluto, e àqueles que ligaram a criação conceitual aos interesses do marketing e da venda de produtos.

Os perigos do marketing são os "universais de comunicação" que eles transmitem, seja na TV ou no outdoor. O que se vê ou lê é que tal carro the proporciona mais liberdade, ou que determinado macarrão lhe dará novas sensações no jantar de domingo. Os conceitos de liberdade e sensação são apenas dois exemplos, entre inúmeros outros, que aparecem associados à promoção comercial de produtos. E a exposição desse conceito pode ser uma linda estrada a beira mar sem lombadas, caminhões e radares limitadores de velocidade, ou ainda uma farta e feliz mesa de jantar onde avós, filhos e netos saboreiam um talharim à bolonhesa. $\mathrm{O}$ objetivo do marketing é criar um conceito para afetar o consumidor com sua exposição enquanto acontecimentos e fazer comprar este macarrão ou este carro e não os outros. (LA SALVIA, 2015, p. 37)

Como toda criação conceitual está relacionada a uma imagem do pensamento $^{5}$, os conceitos criados pelo marketing e pelas disciplinas da comunicação estão relacionados ao estabelecimento da diferença a partir da negação (uma mercadoria merece ser comprada pelo que ela oferece e que as outras não), e também à formação de um consenso, "um denominador comum que sirva para estabelecer um padrão de consumo" (LA SALVIA, 2015 , p. 37). Estas características diferem da filosofia, na medida em que "o consenso é uma regra ideal de opinião" (DELEUZE, 1992, p. 190), de modo que a filosofia, ao criar conceitos em função de questionamentos vitais que se impõem e que obrigam o pensador a buscar formas de se organizar para

${ }^{5}$ Segundo La Salvia (op. cit., p. 38), não seria exagero afirmar a existência de uma "imagem comercial do pensamento" na qual predominam as opiniões de consenso sobre determinados produtos: "A imagem comercial do pensamento seria o momento em que o cogito da mercadoria através das ferramentas do marketing se apropria da criação e elabora um conceito para determinado produto com vistas a vendê-lo mais ao afetar o consumidor que se sente atraído pelas promessas que lhe são feitas e pelo fato de que ele instiga o consenso, o pertencimento a uma comunidade de consumidores. $\mathrm{O}$ bom marqueteiro não é aquele que apenas vende muito um produto, mas aquele que cria um conceito que cola no produto como uma referência, um ser que afeta e faz comprá-lo."

Filosofia e Educação [RFE] - Volume 9, Número 2 - Campinas, SP Junho-Setembro de 2017 - ISSN 1984-9605 - p. 86-97 
enfrentar o caos, assume atualmente a tarefa de resistir a este mundo que rebaixa o pensamento ao transformá-lo numa simples relação de estímuloresposta:

É a propaganda a fazer qualquer cinema, como Deleuze denunciou no livro Imagem-tempo. Um comercial é um tipo de filme pequeno em que um personagem reage aos dados que lhe são oferecidos e escolhe um produto. (LA SALVIA, 2015, p. 39)

Estamos rodeados e imersos em um mundo cada vez maior de informações. Os meios de comunicação se multiplicam e se diversificam a cada dia, nos impondo a tarefa de buscarmos aprender a nos relacionarmos com eles e com aquilo que eles nos oferecem em quantidade e velocidade impressionantes. Mas, e o pensar? O que tem significado pensar neste contexto?

As disciplinas da comunicação fazem funcionar um tipo de relação quase instantânea entre o estímulo recebido e a resposta oferecida, de modo que o ato de pensar parece cada vez mais reduzido à função de recolher dados ou informações e executar a ação escolhida. Este estreitamento entre estímulo-resposta limita as possibilidades de inserção de algo capaz de percorrer este intervalo. Bergson afirma que, em função de um certo estado da matéria cerebral, cria-se um intervalo entre um movimento recolhido e um movimento executado e que são a afetividade, a memória como lembrança e também como contração que o preenchem. Em seus trabalhos com Bergson, Deleuze afirma que foi na linha do ser humano que "o impulso vital soube criar com a matéria um instrumento de liberdade, soube "fabricar uma mecânica que triunfava sobre o mecanismo"” (DELEUZE, 2012, p. 94), de tal forma que somos capazes de fazer escolhas. É esta capacidade de fazer escolhas que nos distancia de um automatismo e de uma total previsibilidade. A vida, segundo Bergson (2005, p. 272), tende sempre a introduzir, na própria necessidade, a maior soma possível de imprevisibilidade e liberdade. Este é o movimento do impulso vital como Junho-Setembro de 2017 - ISSN 1984-9605 - p. 86-97 
exigência de criação. Nessa perspectiva, como podemos resistir ao que Deleuze e Guattari nomearam formação profissional comercial e ao que ela tem determinado como o que significa pensar?

Não pretendemos sugerir um modelo de educação ou uma fórmula pedagógica que se avente capaz de funcionar universalmente, pois, como nos alerta Deleuze "não existe método para encontrar os tesouros e muito menos para aprender" (DELEUZE, 1988, p. 159). É possível, isto sim, compartilhar experiências, apontar caminhos, convidar para compor linhas de fuga, o que tem sido competentemente feito por pesquisadores, professores e estudiosos do campo da educação ou de outros campos, mas que estabelecem pontos de ressonância com a educação ${ }^{6}$, sempre destacando a potência de abertura de mundos que reside no aprender enquanto processo de criação.

É o que parece indicar Gallo em sua proposta de um fazer filosofia na educação, quer dizer, buscar criar ou deslocar conceitos filosóficos para pensar os problemas impostos por este vasto e múltiplo campo a que chamamos educação. Esta tarefa pode nos ajudar na construção de uma educação que afirme sua potência de funcionar como resistência a este mundo tomado pela opinião, pelas comodidades sustentadas por um pensamento do consenso que quer impor uma visão única e definitiva da verdade, que busca conter o movimento criativo do pensar pela instauração de saberes que se pretendem definitivos e que poderiam ser avaliados e assegurados por aqueles que os detêm. Para isso, no entanto, é preciso liberar a própria educação do domínio das opiniões:

A Educação, enquanto campo de saberes, não raramente pode ser vista como uma arena de opiniões. Um campo que poderia primar pela multiplicidade, já que é atravessando transversalmente pela filosofia, pelas diversas ciências, pela arte, tem historicamente buscado uma identidade única, sob o argumento de tornar-se científico, sucumbindo

6 Podemos citar como exemplo, ainda que rapidamente, os autores que têm nos acompanhado na escrita da tese com a qual este trabalho dialoga, como Sílvio Gallo, Hélio Rebello Cardoso Júnior, André La Salvia, Luiz Orlandi, Giuseppe Bianco, Virgínia Kastrup, Cíntia Vieira da Silva e Kátia Kasper, Sandra Corazza, entre outros. 
a esta vontade de verdade, a este mito moderno, criado pelo positivismo. Nesta terra caótica que é o platô Educação, loteada e povoada por metodólogos, sociólogos, filósofos, psicólogos, historiadores, cientistas políticos, além dos chamados "especialistas em educação", grassa a opinião, que se arvora em defensora contra o caos. Estão todos à procura de novidades, estão em busca da "identidade" da Educação. Mas quanto mais prolifera a opinião, dando-se a impressão de que se foge do caos, mais ele nos enreda e nos lança na direção de um buraco negro, de onde já não será possível escapar. (GALLO, 2000, p. 62)

Neste sentido, parece mais interessante levantar questionamentos que possam funcionar como disparadores de movimentos que estabeleçam outras conexões, que instiguem os partícipes envolvidos nas mais diversas processualidades educacionais a colocarem seus problemas e a buscarem formas de respondê-los que conectem os mais variados e inusitados elementos, quer dizer, questionamentos que funcionem como abertura de possibilidades de criações pontuais que modifiquem a forma de perceber o que não era percebido, de dizer o que parecia indizível e de pensar o que se coloca como impensável a um funcionamento ordinário do pensamento.

Ao buscar trabalhar com as ressonâncias entre os campos da filosofia e da educação, podemos dizer que o problema funciona, nessa perspectiva, como ponto de articulação que introduz a diferença fundamental entre saber e aprender, pois o saber está do lado dos resultados, daquilo que deve ser adquirido e conservado, acumulado e acrescentado, e a mudança e o movimento ficam reduzidos - em propostas pedagógicas que sobrevalorizam um certo tipo de conhecimento dominado por modelos apaziguadores $^{7}$ - ao papel de ponte que serve apenas para conduzir de um

\footnotetext{
7 No combate entre caos e pensamento operados por filosofia, ciência e artes e que restauram, em seus próprios encontros intensivos, a possibilidade da criação em cada uma destas diferentes frentes, existe, entre os perigos de se recair na opinião da qual queria-se sair e aquele da precipitação no caos que buscava-se enfrentar, um terceiro perigo destacado por Orlandi (2011, p. 145-154) como operante em algumas práticas de ensino: "aquele que consiste em evitar o confronto com a variabilidade caótica através da
} 
lugar ao outro, a um "intermediário entre o não-saber e o saber" (DELEUZE, 1988, p. 160) ou entre um saber menor e outro saber maior. Por outro lado, o aprender se dá na duração, neste tempo das multiplicidades qualitativas em que só existe continuidade na mudança e que funciona sempre como um limite no sentido de que um novo elemento não o torna maior, mas diferente. É evidente que o aprendizado funciona em um certo sentido e que tem um alvo como ponto de atração das diversas atividades que o povoam, de modo que o saber faz parte do processo, mas que o aprender não pode ser a ele reduzido. É preciso deslocar a atenção para os questionamentos vitais que pedem passagem, pois resolver "é sempre engendrar as descontinuidades sobre fundo de uma continuidade funcionando como Ideia" (DELEUZE, 1988, p. 157) e, neste sentido, as soluções são como pontos de parada que não subsumem o complexo movimento do aprender.

O que nos inquieta, neste sentido, é pensar em que medida as formas de educação que praticamos hoje, quase sempre com uma excessiva valorização de saberes técnicos ${ }^{8}$, é reforçada por uma imagem do que significa pensar que limita o aprender a seu papel de ligação entre um nãosaber e um saber, retirando sua potência de operador intensivo que funciona por disparo nos encontros intensivos e que é capaz de potencializar, em cada partícipe envolvido, o movimento de diferenciação de si mesmo que é a própria vida.

Em $O$ que é a filosofia?, Deleuze e Guattari colocam a formação profissional comercial como uma ameaça à qual é possível resistir justamente pelo fazer filosófico que se dá na e com a segunda idade do conceito: a pedagogia do conceito. Os autores dizem também que não se trata de uma ameaça que possa acabar com a filosofia, pois o marketing e o mercado podem fazer uso da palavra conceito, mas não conseguirão jamais criar conceitos filosóficos, não poderão dizer o acontecimento, não serão

acomodação do corpo e/ou do espírito a modelos de vida, a modelos de conduta, a modelos conceituais, a modelos científicos, a modelos estéticos e assim por diante".

${ }^{8}$ A respeito das relações atuais entre educação e mercado, conferir o discurso de Martha Nussbaum (2015) na Universidad de Antioquia, por ocasião do recebimento do título de Doutora Honoris Causa. 
relativos "a seus próprios componentes" e "aos outros conceitos", e ao mesmo tempo absolutos "pelo lugar que ocupam no plano" e "pelas condições que impõe ao problema" (DELEUZE; GUATTARI, 1997, pp. 3334). A questão, portanto, não é, assim como nunca foi, a morte da filosofia, pois "se há lugar e tempo para a criação de conceitos, a essa operação de criação sempre se chamará filosofia" (DELEUZE; GUATTARI, 1997, p. 17). A questão que se coloca, a nosso ver, é a despotencialização do pensamento, a separação do pensamento e da vida, a negação de que o pensamento cria maneiras de viver, e a circunscrição do pensamento ao seu sentido mais pragmático como forma de negação da própria vida como criação. A filosofia resiste a este processo pela criação de conceitos que são “meteoritos” e não "mercadorias” (DELEUZE; GUATTARI, 1997, p. 20), conceitos que são pedagógicos porque nos mostram, de forma consistente, que "a vida sempre tem algo para nos ensinar na sua variação incessante" (LA SALVIA, 2015, p. 42). E a educação, como pode ela ser lugar e tempo de resistência ao enclausuramento do pensamento a um funcionamento limitante e deformante?

A educação carrega a potência de problematização do que nela se passa e daquilo com que ela trabalha, e é nesta perspectiva que afirmamos anteriormente que o problema funciona como ponto de articulação que introduz a diferença fundamental entre saber e aprender, pois se trata de dar passagem aos questionamentos vitais implicados no aprender e que podem fazer da criação o conector entre modos de pensar e maneiras de viver. Um problema se impõe e exige daquele que com ele se depara, que se reorganize, que se desloque, que faça e permita passar fluxos que pedem outras conexões e recombinações entre elementos que pareciam inconectáveis em outras formas de perceber as coisas.

A nosso ver, uma educação problematizante e auto-problematizante, isto é, que não se fecha em modelos padronizadores nem trata o problema como um simples obstáculo a ser superado por soluções, mas como elemento disparador de conexões que engendram o pensar, funciona no sentido de criar movimentos de resistência ao império da opinião a partir Junho-Setembro de 2017 - ISSN 1984-9605 - p. 86-97 
tanto de uma atenção aos questionamentos vitais que gritam em cada processualidade educacional quanto da criação de outras relações entre saber e aprender que coloquem o próprio pensamento em movimento. Tratase de um fazer educação que promove resistência a essa redução do pensamento a circuitos estreitos entre estímulo recebido e resposta oferecida pela ampliação e multiplicação dos intervalos que aí se inserem, abrindo a matéria à duração e os movimentos de adaptação à indeterminação, de modo que, em meio às necessidades que a vida nos impõe, possamos criar formas diferentes de agir, sentir, perceber e pensar.

Nesse sentido, trazer a noção de pedagogia do conceito para o campo da educação, com o intuito de trabalhar com os pontos de imantação que ela opera entre a filosofia como forma de pensar por conceitos e o fazer educacional que é por ela atravessado, permite perceber que o conceito filosófico possui um estatuto pedagógico, na medida em que nos mostra que uma verdadeira criação - aquela que traz algo novo - é sempre feita em função de um problema que se impõem e exige que se busque outras saídas. A pedagogicidade de um conceito filosófico reside na sua capacidade de nos fazer aprender que existem outras formas de pensar, que é possível inventar outros sentidos e criar novas maneiras de viver, o que aumenta, por sua vez, a potência da educação de invenção de mundos nos quais outros modos de se recriar são possíveis.

\section{Referências}

BERGSON, Henri. A Evolução Criadora. Trad. Bento Prado Neto. São Paulo: Martins Fontes, 2005.

BIANCO, Giuseppe. Otimismo, pessimismo e criação: pedagogia do conceito e resistência. In: Educação \& Sociedade. Campinas, v. 26, n. 93, p. 1289-1308, Set./Dez. 2005. Disponível em <http://www.cedes.unicamp.br>. Acesso em 03 de abril de 2016.

DELEUZE, Gilles. Diferença e Repetição. Trad. Luiz B. L. Orlandi e Roberto Machado. Rio de Janeiro: Graal, 1988. 
. Conversações. Trad. Peter Pál Pelbart. São Paulo: Editora 34, 1992.

. Bergsonismo. Trad. Luiz B. L. Orlandi. 2.ed. São Paulo: Editora 34, 2012.

. Lettres et autres textes. Édition préparée par David Lapoujade. Paris: Les

Éditions de Minuit, 2015.

DELEUZE, Gilles; GUATTARI, Félix. O que é a filosofia?. Trad. Bento Prado Jr. e Alberto Alonso Muñoz. 2.ed. Rio de Janeiro: Editora 34, 1997.

GALLO, Sílvio. O que é a filosofia da Educação? Anotações a partir de Deleuze e Guattari. In: Perspectiva, Florianópolis, v. 18, n. 34, p. 49-68, jul./dez. 2000. Disponível em

\section{$<$ https://periodicos.ufsc.br/index.php/perspectiva/article/view/10418>.}

Acesso em 03 de abril de 2016.

LA SALVIA, André Luiz. A extração de problemas de uma pedagogia do conceito. 2015. 214 f. Tese (doutorado em Filosofia) - Instituto de Filosofia e Ciências Humanas, Universidade Estadual de Campinas, Campinas, 2015.

NUSSBAUM, Martha. Educación para el lucro, educación para la libertad,

Universidad de Antioquia, Medellín, 2015. Disponível em

$<$ http://www.udea.edu.co/wps/portal/udea/web/inicio $>$.

Acesso em 27 dez. 2015.

ORLANDI, Luiz B. L. Deleuze - entre caos e pensamento. In: AMORIM, A. C.; GALLO, S. e OLIVEIRA JR, W. M. (orgs.). Conexões - Deleuze e Imagem e Pensamento. Petrópolis, RJ: De Petrus; Brasília, DF: CNPq, 2011, p. 145-154. 